\title{
UNA APROXIMACIÓN AL ACTO CAMBIARIO DESDE LA TEORÍA DEL NEGOCIO JURÍDICO
}

\author{
AN APPROACH TO THE EXCHANGE \\ ACT FROM THE THEORY OF LEGAL BUSINESS
}

Piero Da Giau Roose

Universidad Femenina del Sagrado Corazón, Perú

\section{Resumen}

Los principios generales del derecho constituyen una cosmovisión o aspiración generadora de pautas orientadoras o directrices que van más allá de la labor creadora del derecho positivo; abarcan no solo el acto generador de la norma jurídica, sino también los mecanismos de interpretación y de integración jurídica. Empero, cada área del derecho se rige por principios especiales que les son propios y que generan características individuales que las independizan. El presente artículo busca relacionar las normas que rigen al negocio jurídico con aquellas que tratan sobre el derecho cartular o cambiario, intentando demostrar las peculiaridades inherentes a esta última y especialísima área del derecho. Partiremos desde una perspectiva histórica y culminaremos en la demostración normativa y jurisprudencial, reforzada por la dogmática en ambos campos del conocimiento jurídico.

Palabras clave: principios generales de derecho, principios cambiarios, integración, interpretación, negocio jurídico, derecho cambiario, título valor, error, forma, formalidad, capacidad, manifestación de voluntad, literalidad, documentación, especialidad, antinomias 


\begin{abstract}
The general principles of law are a worldview or aspiration that generate guidelines that go beyond the creative work of positive law, covering not only the act generator of the legal norm but also the mechanisms of interpretation and legal integration. However, each area of law is ruled by special principles that are its own and that generate individual characteristics that make them independent. This article seeks to relate the rules that govern the legal transactions with those that deal with the exchange law, trying to demonstrate the singularities inherent in this special area of law, we will start from a historical perspective and culminate in the normative and jurisprudential demonstration, reinforced by dogmatic in both fields of legal knowledge.
\end{abstract}

Keywords: General principles of law, exchange principles, integration, interpretation, legal transactions, exchange law, securities, error, form, formality, capacity, manifestation of will, literality, documentation, specialty, antinomies.

\title{
1. El acto cartular como especie del acto jurídico
}

Hace algunos años, el maestro Marcial Rubio Correa publicó un libro que todos los alumnos de una generación utilizamos para ingresar a la hermosa ciencia del derecho: El sistema jurídico. Fue mucho más que un simple título o encabezado de una labor editorial que se convertiría en el pórtico de ingreso a la carrera de todo novel estudiante de leyes. Dicho texto era, en el fondo, la continuación de otro trabajo editorial peruano muy importante: Introducción al derecho, del maestro sanmarquino Mario Alzamora Valdez.

Fue muy común escuchar durante años la tradicional definición del derecho como «Un conjunto de normas jurídicas destinadas a regular la conducta humana intersubjetiva». El sistema jurídico, de Marcial Rubio, puso fin a esa repetición memorística que llevaba a los jóvenes estudiantes a una afirmación imprecisa, por no decir errada o equivocada.

El Diccionario de la lengua española registra para el término conjunto (del latín coniunctus) diversas acepciones; la primera de ellas es «unido o contiguo a otra cosa»; otra de ellas, «totalidad de los elementos o cosas poseedoras de una propiedad común, que los distingue de otros; p. ej., los números pares». En efecto, podríamos afirmar que el derecho aglutina a una categoría especial de normas: las jurídicas. Dichas normas jurídicas, sin embargo, no se hallan 
simplemente unidas, sino que conforman un complejo sistema regido por los principios de jerarquía, cronología y especialidad.

Si no existieran los principios de jerarquía normativa - el cronológico y el de especialidad de la norma-, sería inviable superar las antinomias jurídicas. Estas existen y existirán, puesto que todo sistema jurídico es y será una creación humana, y, por tanto, imperfecto. Las antinomias son inherentes a él, y por esta razón contamos con los tres principios citados con anterioridad, gracias a los cuales se hace posible superar las referidas antinomias en el sistema normativo.

La antinomia implicará, por consiguiente, la aparente aplicación simultánea de dos normas jurídicas a un mismo hecho recogido de manera fragmentada por el presupuesto normativo, supuesto de hecho, fatiespecie (del latín 'figura del hecho') o Tattbestand (en alemán). En algunos casos será suficiente la aplicación del principio de jerarquía normativa. ¿Pero qué ocurre si ambas normas corresponden a una misma jerarquía o entraron en vigor al mismo tiempo? Ante dicho supuesto se tendrá que aplicar el principio de especialidad.

En el caso que es materia del presente análisis, partiremos de una afirmación concreta: tanto las normas contenidas en el libro II del Código Civil (Libro del Acto Jurídico) como las normas contenidas en la Nueva Ley de Títulos Valores (Ley 27287, en adelante NLTV) tienen rango de ley. Desde el punto de vista jerárquico, ambos cuerpos normativos corresponden a una misma jerarquía, independientemente de que el Código Civil peruano haya entrado en vigencia en 1984; y la NLTV, dieciséis años después, en el año 2000.

La teoría del negocio jurídico es mucho más reciente de lo que imaginamos, pues si bien es cierto que el negocio romano es considerado un antecedente de la teoría negocial, podemos afirmar que en Roma no existió la teoría del negocio jurídico, la cual se empieza a formar a partir del trabajo de la escuela de la pandectística, surgida durante el auge del Sacro Imperio Romano Germánico; en Roma se estudiaron las diversas instituciones jurídicas, tales como la patria potestad, la potestad dominica, los esponsales, el matrimonio, el concubinato, la tutela, la curatela, la capitis diminutio, el dominio, la posesión, la sucesión, los testamentos, los contratos, la responsabilidad extracontractual, los efectos de las obligaciones, la inejecución y las modalidades, etcétera.

A diferencia de los jurisconsultos romanos, que estudiaron diversas instituciones de manera fragmentaria e independiente, los pandectistas buscaron los elementos comunes o el hilo conductor entre cada una de ellas. Cuando hablamos de la manifestación, la capacidad, la forma, el fin y el objeto, nos 
referimos a elementos inherentes que se hallan en los diversos negocios. De la misma manera, la alusión al error en la declaración o al error en la representación significa que abstraemos aspectos correspondientes no a una sola e individual institución o campo del quehacer jurídico, sino, en general, a los diversos actos que los individuos pueden realizar; esto abarcará el error de cálculo, el error indiferente, etcétera.

El gran aporte de la pandectística es resaltado por el maestro Luigi Mengoni:

Aquí sale a la luz la aporía central de la dogmática tradicional de matriz Pandectística [...] Los conceptos de la ciencia jurídica (conceptos dogmáticos) diferenciados en tres clases de conceptos: fattispecie (por ejemplo, en la dogmática del derecho privado: acto jurídico, negocio jurídico, contrato, hecho ilícito, etc.) $)^{1}$.

En similar razón, el maestro Jorge Basadre Ayulo afirma:

A partir del siglo XII se recibe como sistema regulador el Corpus Iuris Civilis. Se inicia, pues, ya un proceso de recepción selectiva y consuetudinaria de la legislación de Justiniano entre cuyas disposiciones se adherían normas propias. La producción jurídica se expresó en el Sacro Imperio, en la elaboración de leyes dictadas por el emperador con la aprobación de los maiores en las Dietas imperiales².

Por su parte, el derecho cambiario puede ser mucho más antiguo de lo que imaginamos; en realidad, es anterior al desarrollo de la teoría negocial, inexistente en Roma, más allá de que el genio romano haya cimentado en él su desarrollo posterior. Se afirma que el cambio efectuado por los comerciantes se originó en Grecia; a dichos cambistas se los llamaba trapezitas, palabra proveniente de trapesa ('mesa en la que se efectúa el préstamo de dinero').

Es lógico pensar que el derecho cambiario tiene un origen ancestral, puesto que, como bien sabemos, la primera fuente del derecho mercantil son los usos de los comerciantes. Existen pocas fuerzas humanas mayores que la ambición del hombre, por lo que el derecho positiviza los usos siempre con posterioridad. El influjo de los comerciantes siempre es más intenso que la labor de los juristas. No es de extrañar, por tanto, que el derecho cambiario tenga

1 Leysser Luggi León Hilario (coord.), Derecho de las relaciones obligatorias (Perú: Jurista Editores, 2007), 36.

2 Jorge Basadre Ayulo, Historia del derecho (Lima: Editorial San Marcos, 1997), 283. 
antecedentes históricos muchos más profundos que la teoría negocial, pese a variadas posiciones discordantes que señalan sus orígenes en la Edad Media. Una de estas la expresa el maestro Lisandro Peña Nossa:

A pesar que los pueblos antiguos como Babilonia, Egipto, Grecia, Rodas y Fenicia (a través de su colonia Cartago) practicaron de manera muy eficaz el comercio, no se tiene vestigio alguno de la utilización de los papeles de comercio, que sí, de acuerdo con los datos históricos, aparecen en la edad media, en la que mediante el surgimiento del comercio se hacía necesario cambiar las formas tradicionales de circulación de bienes, como el trueque o la circulación física de los bienes y la compraventa, por una circulación más ágil: la utilización de los documentos que hoy se denominan títulos valores ${ }^{3}$.

Queda claro, entonces, que la teoría negocial tuvo su desarrollo a partir de los cimientos del negocio romano, pero que se constituyó a partir del influjo de la escuela de la pandectística, muchos siglos después, a través de un estudio sistemático del Corpus Iuris Civilis desarrollado bajo el influjo justinianeo, vale decir, de la exégesis y de la glosa de los más importantes textos generados por el genio romano: las constituciones imperiales, las novelas, las pandectas, el digesto, etcétera.

Por su parte, la teoría cambiaria siguió un rumbo autónomo generado por el influjo de los comerciantes de las ciudades estado de la Edad Media. El auge del comercio entre ellas queda registrado incluso en las más hermosas obras de la literatura universal, entre ellas El mercader de Venecia, una de las más importantes creaciones de William Shakespeare. La obra gira alrededor de la ejecución de un pagaré, titulo valor utilizado para eludir la prohibición del cobro de los intereses que la Iglesia repudiaba hasta antes de la llegada de la doctrina de Santo Tomás de Aquino, quien flexibilizó conceptos, entre ellos la prohibición del cobro de un fruto civil: los intereses.

En la citada pieza teatral podemos verificar la íntima relación entre el comercio, el derecho, la política, la filosofía y la religión. Atribuir a Shakespeare el genio de la ficción sería injusto: en su obra se encuentra la sabiduría de un jurisconsulto. Podemos afirmar, sin exagerar, que, antes de escribirla, el autor no solo revisó el derecho en general, sino también el derecho cambiario en particular. El insigne dramaturgo estudió, asimismo, el numus non parit numus

3 Lisandro Peña Nossa, Curso de Títulos-Valores (Bogotá: Themis, 1992), 3. 
como parte del pensamiento aristotélico que generó la proscripción del cobro de intereses como fundamento de su filosofía, recogida a su vez por el cristianismo en el evangelio de san Lucas: «Haced el bien y prestad sin esperar nada» (Lc 6: 35-36).

El desarrollo del derecho cambiario siguió un camino propio e independiente del desarrollo de la teoría negocial. La cambial o letra de cambio, como evolución y metamorfosis de un contrato medieval denominado «contrato de cambio trayecticio», generó el surgimiento de una disciplina autónoma regida por principios propios y peculiares, en la que, pese a compartir aspectos comunes con la teoría negocial, adquiere características que le son propias y únicas.

El derecho cartular ha desarrollado, desde la Edad Media hasta el día de hoy, toda una teoría propia e independiente regida por principios que le son propios y exclusivos, tales como la autonomía cambiaria, la abstracción cambiaria, el principio de documentación, el principio de circulación, el principio de formalidad, el principio de solidaridad cambiaria, entre otros.

\section{Los elementos del acto jurídico y su vinculación con el derecho cambiario}

En los títulos valores hallamos una sucesión de actos jurídicos unilaterales que se incorporan de manera sucesiva al instrumento o soporte cartular (cartón, cartulina, papel). La entrada o momento de ingreso de un título valor al mercado es denominada emisión, libramiento o giro; este acto no es más que la puesta en circulación de un instrumento cartular al comercio. Los sujetos pueden emitir letras de cambio, cheques, pagarés, warrants, certificados de depósito, facturas negociables, etc.

Entenderemos por emisión, en primer lugar, un acto jurídico cartular, formal y abstracto que requiere de capacidad del emitente o emisor. En tal sentido, le será de aplicación el numeral 1 del artículo 140 del Código Civil, modificado por el artículo 1 del Decreto Legislativo 1384, publicado el 4 de septiembre de 2018 en el diario oficial El Peruano, exigiéndose, por tanto, «1. Plena capacidad de ejercicio, salvo las restricciones contempladas en la ley».

En lo referente a la capacidad de ejercicio, es evidente que la teoría negocial y el derecho cartular comparten el elemento esencial en todos aquellos casos en los que un sujeto pretende emitir o girar un título valor. No obstante, encontramos jurisprudencia cambiaria que es necesario analizar y comentar, 
puesto que grafica las diferencias existentes entre los actos jurídicos en general y los actos cartulares en especial. Tal es el caso de la jurisprudencia cambiaria referida a la firma a ruego, la cual es regulada en el artículo 107 del Decreto Legislativo 1049, Decreto del Notariado, en los siguientes términos:

Testigo a Ruego.- Si alguno de los otorgantes del documento no sabe o no puede firmar, lo hará una persona llevada por él a su ruego; en este caso el notario exigirá, de ser posible, la impresión de la huella digital de aquél, certificando la firma de la persona y dejando constancia, en su caso, de la impresión de la huella digital.

Lo primero que se desprende del artículo transcrito en el párrafo precedente es que, para proceder a la firma a ruego, el «firmante» a ruego (el solicitante) es una persona capaz, inteligente y con discernimiento; en caso contrario, se utilizaría la representación legal a través de un curador designado por la judicatura. En la firma a ruego, se entiende que el solicitante posee capacidad, mas no posibilidad corporal de efectuar o plasmar la firma o, en todo caso, desconocimiento del lenguaje escrito; en el último supuesto, nos hallamos, ergo, frente a un analfabeto.

En lo referente a la posibilidad corporal, podríamos hallarnos ante diversos supuestos no detallados en la acotada norma procesal, los cuales quedan en la esfera de la discrecionalidad de aquel que ejerce la función notarial. Tales supuestos pueden ser la imposibilidad de firmar por razones de salud, como un excesivo temblor en las manos o extremidades generado por un sinnúmero de dolencias que no afectan el discernimiento; la persona es hábil, inteligente y discierne, pero no puede firmar. Otros supuestos físicos podrían encajar en la ausencia de manos o extremidades que le impidan estampar su firma. También podemos considerar los casos de ceguera absoluta; si bien es cierto que en la doctrina se diferencia la firma a ruego de la firma de los ciegos, en nuestra legislación no hallaríamos diferencia alguna, puesto que un invidente podría optar por la firma a ruego.

Una persona con plena capacidad de ejercicio puede, entonces, recurrir a la firma a ruego, ante notario público, con la presencia de dos testigos a ruego. En la diversidad de actos jurídicos - ya sean unilaterales, bilaterales o plurilaterales- la firma a ruego se halla contemplada en nuestro derecho positivo; permite, a su vez, la no discriminación y la posibilidad de que un sujeto con dolencias físicas o limitaciones culturales pueda participar sin necesidad de representantes en uno o más actos jurídicos. 
Ahora bien, trataremos el tema de la firma a ruego en el campo cartular, y demostraremos las diferencias que se generan entre la teoría negocial y de derecho cartular, en este tema peculiar y concreto. En el ámbito jurisprudencial hallamos la siguiente casación:

La firma en los títulos valores no puede ser suplida por las iniciales, una cruz, la impresión digital por no saber firmar y ni siquiera la firma a ruego con intervención de fedatario público, ya que los requisitos contemplados en el artículo siete de la Ley de Títulos Valores son específicos; de allí que, quien no sabe o no puede firmar, solo puede crear títulos valores mediante apoderado facultado para hacerlo; resultando en virtud de ello el requisito de la firma, un elemento necesario en el título valor. El mandatario debe firmar de puño y letra al modo usual que emplea, como si fuese el poderdante; ya que si no lo hiciese así, aunque indique el nombre del mandante, no lo obligará4 .

La casación mencionada en líneas anteriores nos lleva a un primer punto de confrontación entre la teoría negocial y el derecho cambiario. Esto nos permite plantear las siguientes interrogantes: ¿por qué motivo el acto cartular no admite la firma a ruego? ¿Qué principio cambiario genera el tratamiento distinto entre la generalidad de los actos jurídicos respecto del acto cartular?

Hemos señalado anteriormente que en los títulos valores se van incorporando de forma sucesiva actos jurídicos unilaterales. Desde el momento de la puesta en circulación de un título valor, apreciamos una continuidad de actos, como la aceptación, la reaceptación, la prórroga, o el endoso. En todos ellos queda meridianamente claro que no estamos frente a contratos o actos jurídicos bilaterales o multilaterales, sino frente a actos jurídicos unilaterales y en algunos casos no recepticios. Debemos precisar que estos actos jurídicos unilaterales son también en muchos casos formales y abstractos.

En la historia del desarrollo de la teoría cartular hallamos el principio de la apariencia, que luego pasó a alimentar al derecho registral y, en especial, de raigambre inmobiliaria. El principio de la apariencia solo puede subsistir a través de mecanismos óptimos de publicidad. En el plano registral es evidente que será la publicidad que el registro otorga; en el campo cartular, será el propio título valor el continente de la publicidad. En tal sentido, la publicidad como principio en los títulos valores requiere de otro principio importante,

4 CAS 2928-00 Lima, El Peruano, 2 de febrero de 2001. 
recogido en el texto de la NLTV: el principio de literalidad, cuyos efectos se complementan con el principio de formalidad. Al respecto, es menester recordar lo afirmado por el maestro Manuel Broseta al explicar el principio de literalidad:

Se refiere al contenido del título valor y viene a significar que la naturaleza, el ámbito y el contenido del derecho incorporado se delimitan exclusivamente por lo que se menciona en la escritura que consta en el documento, de tal modo que, refiriéndose a esta característica, se pudo afirmar históricamente que lo que no está en el documento no está en el mundo 5 .

Esta cita nos aproxima a la literalidad cambiaria de manera magistral, puesto que podemos entender que en materia cambiaria no es posible hablar de actos desprovistos de «escrituralidad» y que esta, además, no esté acompañada de la nota de formalidad. Para que un instrumento pueda ser considerado un título valor, debe reunir todos los requisitos formales que la ley prevé.

A diferencia de los actos jurídicos en general, en materia cambiaria no es factible hablar de actos verbales, la escritura plasmada en el título genera efectos conforme al principio de la literalidad, $y$, de esa forma, los sujetos cambiarios conocen perfectamente los derechos que pueden extraer del título valor. De la misma manera, el título y el derecho contenido e incorporado en él se explican a partir del principio de la apariencia. La confluencia de los diversos principios señalados de forma previa hace que en materia cartular no sea posible hablar de actos jurídicos verbales. Los principios que rigen al derecho cambiario lo convierten en una rama única y peculiar.

Sin embargo, será materia de análisis el inciso 4 del artículo 140 del Código Civil: «Observancia de la forma prescrita bajo sanción de nulidad». Sobre el particular, es importante precisar que los elementos esenciales son necesarios para que el acto jurídico sea considerado válido; para lograr esto, empero, podemos evidenciar que deben confluir cuatro de los cinco elementos contenidos en el mencionado artículo. El elemento esencial contenido en el inciso citado será de aplicación única y exclusiva en los actos regidos por una formalidad ad solemnitatem (no «forma ad solemnitatem», como de manera errónea considera o denomina equivocadamente el Código Civil, confundiendo el concepto de forma con el de formalidad).

5 Manuel Broseta Pont, Manual de derecho mercantil (Madrid: Tecnos, 1994), 622. 
Si quisiéramos comparar los títulos valores (como continentes de una serie sucesiva de actos jurídicos unilaterales) con los actos jurídicos en general, podríamos evidenciar que, si bien es cierto que pueden existir actos jurídicos no regidos por una forma solemne - los cuales corresponden incluso a la gran mayoría de ellos-, no es admisible, en sentido opuesto, la existencia de títulos valores no regidos por una férrea exigencia formal.

El principio de formalidad cambiaria exige que los instrumentos cartulares contengan todos los requisitos formales de carácter particular y general; en caso contrario, no podrán ser considerados títulos valores. En consecuencia, los actos cartulares sucesivos incorporados en los títulos valores se rigen por la formalidad, la cual, a nuestro parecer, se relativiza en determinados casos excepcionales, tal como se verifica en el caso de la voluntad del propio legislador o del juzgador en contados y limitados supuestos.

La formalidad cambiaria, a diferencia de lo afirmado por la doctrina tradicional, se flexibiliza en determinadas situaciones que abordaremos más adelante, cuando desarrollemos el error en la teoría negocial y el tratamiento del error en el campo cartular. Por ejemplo, en el importe de un título valor, en caso de discrepancia entre la suma expresada en números o la expresada en letras, prevalecerá la menor; se retoma así el criterio del Código de Comercio de 1902, del cual nos apartamos durante los veintitrés años de vigencia de la derogada Ley 16587 (Libro de los Títulos-Valores), y donde prevalecía la suma expresada en letras por encima de la expresada en números.

En lo referente a la finalidad del acto, el Código Civil peruano exige que esta sea lícita, es decir, que la motivación determinante en el acto no sea contraria al ordenamiento jurídico ni reciba reproche alguno. Tanto la finalidad como la licitud están relacionadas con la validez del acto jurídico; en ese sentido, es perfectamente posible que los títulos valores sean utilizados con fines contrarios al ordenamiento jurídico; pueden perseguir un fin ilícito, como, por ejemplo, la emisión de un cheque con la finalidad de cometer un delito de estafa genérica o alguna modalidad de estafa, como el delito de libramiento indebido. 


\section{El error en los actos jurídicos y el error en los instrumentos cartulares}

El error es inherente a la condición humana y a la naturaleza imperfecta del ser humano. La teoría del acto jurídico clasifica y subclasifica el error. Se habla principalmente del error en la declaración y del error en la representación. Sobre el particular, el maestro chileno Avelino León Hurtado expresa: «El error es el falso juicio que se tiene de una cosa, un hecho, de una persona o del principio jurídico que se presupone. De aquí que el error puede ser de hecho y de derecho» ${ }^{6}$.

No es inusual que una persona declare algo diferente de lo que en el fondo desea, la discrepancia entre lo que realmente se desea y lo que se declara es denominada error en la declaración. Debe quedar perfectamente aclarado que esa discrepancia entre lo que se encuentra en nuestra psiquis y lo que declaramos debe estar desprovista de intencionalidad, pues muchas veces se confunde al error con figuras como el dolo, el fraude o la simulación.

Por su parte, el error en la representación corresponde a la disconformidad entre lo que existe en la realidad y lo que se representa en nuestra psiquis, como, por ejemplo, las características de un objeto, sus cualidades, el volumen, dimensiones, etc. Todo lo que no es objeto es sujeto y todo lo que no es sujeto es objeto. La imperfecta representación de los objetos en los sujetos corresponde a lo que la doctrina denomina «error en la representación».

El maestro italiano Vittorino Pietrobon nos dice:

El desacuerdo fundamental en la teoría del negocio jurídico corresponde, como se sabe, a la antítesis entre la sustancia y la apariencia de las cosas, antítesis que se pone especialmente de relieve en aquellos hechos que, por su misma naturaleza, escapan al control de los sentidos ${ }^{7}$.

Podemos apreciar la sencillez de los términos utilizados por el destacado maestro italiano; las palabras sustancia, apariencia y antítesis nos explican en gran medida la naturaleza del error. El contacto de los hombres con la realidad se produce mediante los sentidos; es a través de ellos que nuestra mente o conciencia toma conocimiento de los objetos, del mundo exterior. Cuando no

6 Avelino León Hurtado, La voluntad y la capacidad en los actos jurídicos (Santiago de Chile: Editorial Jurídica de Chile, 2000), 151.

7 Vittorino Pietrobon, El error en la doctrina del negocio jurídico (Madrid: Editorial Revista de Derecho Privado, 1971), 1. 
existe equivalencia entre el objeto y su representación en el sujeto, estaremos frente al error en la representación; por el contrario, cuando no exista equivalencia sincera entre nuestra voluntad y lo declarado, nos hallaremos frente al error en la declaración.

Por su parte, el maestro chileno Víctor Vial del Río señala:

En el lenguaje corriente no es lo mismo la ignorancia que la equivocación. Quien ignora algo no tiene noción de una cosa; en cambio quien se equivoca tiene una noción, pero errada. Jurídicamente el error — constituido por una falsa representación de la realidad— puede deberse a la ignorancia o equivocación ${ }^{8}$.

En la doctrina encontraremos una gran cantidad de supuestos referidos al error, como el error in negotio, el error sobre la naturaleza del contrato, el error sobre el objeto del contrato, el error sobre el objeto de la prestación, el error indiferente, el error en la cualidad, el error de cálculo, el error sobre la cantidad, el error sobre el precio, el error de hecho, el error de derecho, el error obstativo, el error esencial, el error indiferente, el error en la designación de lo querido, el error de previsión, el error sobre el motivo, el error incidental, entre otros.

Siendo que el presente artículo no tiene por objeto el tema del error en sí, sino la comparación entre el error en general dentro de la teoría negocial y el error en la teoría cartular, se torna imposible desarrollar cada uno de los supuestos previamente indicados en el párrafo precedente.

Error de cálculo, error sobre la cantidad y error sobre el precio son supuestos que deben ser desarrollados y explicados antes de iniciar la comparación entre el error en la teoría negocial y el tratamiento del error en el derecho cambiario y de manera específica y concreta en la ley vigente, es decir la NLTV.

En lo referente al error en la cantidad o error in quantitate, el maestro Manuel Albaladejo señala lo siguiente: «Versa sobre la cantidad, bien sea en cuanto a las dimensiones de la cosa, o en cuanto al número de unidades que encierra, o en cuanto a la cifra por la que se adquiere» ${ }^{9}$.

Por su parte, el maestro peruano Juan Espinoza Espinoza no solo desarrolla el error de cálculo, sino también los efectos del precitado vicio de la voluntad, señalando al respecto lo siguiente:

8 Víctor Vial del Río, Teoría general del acto jurídico (Santiago de Chile: Editorial Jurídica de Chile, 2003), 78.

9 Manuel Albaladejo, El negocio jurídico (Barcelona: Bosh, 1993), 143. 
Se sostiene que el error sobre la cantidad es un verdadero y propio error sobre el objeto. Asimismo el error de cálculo puede ser rectificado art. 1430 c. c. ita. Y (204 c. c.). También este remedio puede adscribirse a la función conservativa del contrato $^{10}$.

En materia cambiaria, analizaremos supuestos muy peculiares de error que se desarrollan en la doctrina cartular y se plasman en el articulado de la NLTV, pues es muy usual hallar supuestos de error en los instrumentos cartulares, como, por ejemplo, aquellos que se derivan del importe consignado en los títulos valores. Como bien sabemos, el importe de un título valor se expresa en números y letras, debiendo existir correspondencia entre la suma expresada en números y la expresada en letras.

La condición humana del girador de un título puede llevar a veces al error de los importes consignados en el instrumento cambiario. En este caso, a diferencia de la teoría negocial, no estaremos frente a la posibilidad de aplicar la rectificación, puesto que en materia cartular será de aplicación la norma especial. En tal sentido, la NLTV establece que, en caso de discrepancia entre el importe escrito en letras y el importe escrito en números, prevalecerá la suma menor. La fórmula que recoge la NLTV retorna al criterio establecido en el Código de Comercio de 1902, del que nos apartamos durante la vigencia de la derogada LTV; esta establecía que, de presentarse discrepancia entre los importes, prevalecía la suma expresada en letras. La acotada norma tenía como fundamento precisamente que era más factible cometer un error en la suma expresada en números que en el importe expresado en letras.

Art. 3.- Si el importe del título valor estuviere expresado en palabras y en cifras, en caso de diferencia prevalecerá la suma escrita en palabras. Si la cantidad estuviere indicada varias veces en palabras o en cifras, el valor del documento será el señalado por la suma menor ${ }^{11}$.

Siendo que la gran mayoría de títulos y formatos estandarizados contienen segmentos establecidos para señalar el importe en letras y números, el criterio de la LTV, concordante con el artículo 6 del Reglamento de la Haya de

10 Juan Espinoza Espinoza, Acto jurídico negocial: análisis doctrinario, legislativo y jurisprudencial (Lima: Gaceta Jurídica, 2008), 404.

11 Ley de Títulos Valores (Ley 16587). 
1912 y el apartado 1 de la Ley Uniforme de Ginebra, era el de otorgar preferencia a la suma escrita en letras respecto del importe escrito en números. El fundamento del error en números es más usual que el que expresamos al utilizar palabras; un instante de confusión puede llevarnos a colocar uno o más ceros o dígitos erróneamente, situación menos probable cuando recurrimos a las palabras.

Con la entrada en vigencia de la NLTV, el criterio se modifica y, en caso de discrepancia entre el importe escrito en números o el importe escrito en palabras, siempre prevalecerá la suma menor. Como hemos indicado con anterioridad, el legislador ha retornado al criterio del Código de Comercio de 1902.

La primera interrogante válida sería: ¿cuál es el motivo o razón de haber retornado al criterio del Código de Comercio de 1902, si, en efecto, el error del importe expresado en números es mucho más usual que el error del importe expresado en palabras? La respuesta parece hallarse en aspectos procesales y adjetivos, mas no sustantivos.

Los instrumentos cambiarios aspiran a convertirse en títulos ejecutivos, conforme se desprende del inciso 4 del artículo 688 del Código Procesal Civil de 1993; en tal sentido, aparejan ejecución, ergo, presunción de reconocimiento de derecho, así como una rápida y veloz ejecución. Por tal razón, es comprensible que la fórmula vigente sea aquella en la que prevalece la suma menor, sin perjuicio de que el ejecutante pueda exigir la diferencia en la vía que corresponda, eventualmente, la causal.

Espinoza Espinoza, citando al maestro italiano Vincenzo Roppo, no solo desarrolla el remedio en líneas anteriores, sino que, además, procede a diferenciar el error de cálculo del error en la cantidad señalando:

La doctrina tanto extranjera, como nacional, pretende diferenciar el error de cálculo del error en la cantidad, cuando — evidentemente- la última parte del art. 204 c.c. se refiere al error en la cantidad como un resultado de cálculo. Por ello, se sostiene que el error de cálculo y el error de cantidad no se excluyen: la primera figura comprende a la segunda, o la segunda es una especie calificada de la primera.

Sin perjuicio de lo señalado por el maestro Roppo, vale la pena preguntarnos qué ocurre con el error literalizado en los instrumentos cartulares, ¿Se podrá aplicar al error plasmado en los títulos valores la teoría negocial en puridad? ¿Existirá la necesidad de aplicar el principio de especialidad para darle 
al error literalizado en un título valor un tratamiento distinto? ¿Qué explica de por sí esta comparación?

Intentaremos desarrollar el cuadro comparativo entre la figura del error en la teoría negocial y el error en el derecho cambiario, con las peculiaridades derivadas de la aplicación de los principios que los rigen. Citaremos, en primer término, al maestro José Luis García Pita y Lastres, quien, respecto del principio de literalidad cambiaria, expresa:

El primero de esos otros rasgos o propiedades características del título-valor, y que se esconde bajo la referencia a la "incorporación", consiste en que la documentación del derecho en el título produce el sometimiento de ese derecho al Principio de "Literalidad" [...] en ese sentido la Literalidad del título — se ha dicho— es la visibilidad del derecho [...] hasta el punto de que, en una formulación maximalista de esta característica, se ha llegado a afirmar "Lo que no está en el título, no está en el mundo"12.

Si aplicamos la formulación maximalista «Lo que no está en el título no está en el mundo», será fácil comprender cómo el tratamiento del error en la declaración no podrá ser similar en el acto cartular respecto del acto jurídico en general. Cuando estamos frente a un título valor, encontramos la aplicación concreta de los principios de incorporación y literalidad; los sujetos cartulares conocen perfectamente cuáles son los derechos que pueden extraer del instrumento. La alegación de error se ve con claridad limitada a lo que fluye de la literalidad, así como del derecho incorporado y literalizado en el instrumento; por tanto, la alegación de error no sería materia de discusión en el derecho cambiario con la misma intensidad que en la generalidad de actos jurídicos.

Si derecho e instrumento forman una unidad derivada de la icástica o de la incorporación o simbiosis de derecho e instrumento, se deduce, por tanto, que la alegación del error en la literalidad no será válido en un instrumento cartular que da origen a un proceso único de ejecución. En ese sentido, la discrepancia entre la voluntad exteriorizada en la literalidad y la real intención del sujeto, solo hallará solución en fórmulas legales, mas no en la interpretación o búsqueda de la verdadera intención o deseo del que la exteriorizó, sin perjuicio de recurrir a la vía causal, en la cual ya no son aplicables los princi-

12 José Luis García-Pita y Lastres, Introducción al derecho de los títulos valores y de las obligaciones mercantiles (Santiago de Compostela: Tórtulo, 2002), 90. 
pios que rigen al derecho cambiario; ergo, en este, y dentro del proceso único de ejecución, no habrá lugar para la búsqueda de la verdadera intención ni para escudriñar la existencia del error; será la ley la que fije la fórmula correspondiente. En ese aspecto, por ejemplo, en lo referido al importe de un título valor, el artículo 5.2 de la NLTV señala:

En caso de diferencia del importe del título valor, expresado sea en letras o en números o mediante codificación, prevalecerá la suma menor; sin perjuicio que el interesado pueda hacer sus mayores derechos frente al obligado, por la vía causal.

En el acto jurídico, la verdad no se pierde por el error; de ahí la máxima «errore veritas... non amittur». Por el contrario, en el acto cartular que da origen al proceso único de ejecución, al error lo seguirá una fórmula legal impuesta por el legislador. Como antes hemos señalado, la fórmula legal incorporada al texto de la ley cambiaria vigente ha sido recogida también de un antiguo aforismo romano: «In dubio semper id, quod minus est, debetur» ('En la duda se debe siempre aquello que es menos' $)^{13}$.

Otra situación que merece ser analizada es la que se refiere al signo monetario consignado en un título valor cuyo tratamiento, en caso de error, será distinto del que se le daría a un importe consignado en un contrato, una factura o diversos instrumentos privados. Es posible que un sujeto, por error, consigne en un instrumento privado un signo monetario equivocado. Tal vez su intención, o la intención común, es obligarse en moneda nacional o, quién sabe, en moneda extranjera. Si el error en la declaración correspondiese a un instrumento privado, en general, regido por las normas propias del acto jurídico, tendríamos que proceder a hallar cuál fue la verdadera y común intención de los contratantes; procederíamos a interpretar el acto jurídico restringiéndolo al deseo de obligarse en una u otra divisa; se buscaría, en lo posible, la conservación del acto y su verdadero sentido para tal fin. Las teorías de la declaración, de la confianza o de la responsabilidad se plasman en diversos artículos de nuestro Código Civil. Existirá, a su vez, una notoria diferencia entre la interpretación de la ley o de las resoluciones judiciales y la interpretación de los actos jurídicos o negocio de derecho privado; en tal sentido, el maestro italiano Emilio Betti señala:

13 Jaime Mans Puigarnau, Los principios generales del derecho: repertorio de reglas, máximas y aforismos jurídicos con la jurisprudencia del Tribunal Supremo de Justicia (Barcelona: Bosch, 1978), 249. 
Junto con las resoluciones en las que se manifiesta, para la actuación de la ley, una competencia normativa de órganos reglados hacia otros sujetos a ellos subordinados, son valorados y disciplinados por el Derecho otros tipos de actos en los que se manifiesta únicamente el poder de dictar para los propios intereses que se establecen ${ }^{14}$.

La interpretación de la ley difiere de forma notable de la interpretación de los actos negociales. Hallar el sentido de la norma no es lo mismo que hallar el sentido de la común intención de los contratantes, o de la intención unilateral, e incluso de los actos no recepticios. Siguiendo y profundizando en el tema, encontramos lo mencionado por el maestro Ricardo Guastini: «Naturalmente, existe una gran variedad de textos jurídicos sujetos a interpretación: fuentes del derecho (la constitución, las leyes, los reglamentos, etc), actos de autonomía privada (contratos, testamentos, etc.), actos jurisdiccionales (sentencias), actos administrativos y otros» ${ }^{15}$.

En materia cambiaria, buscar el sentido correcto de la divisa a la cual las partes o sujetos cartulares pretendían obligarse tiene una solución o fórmula legal elaborada por el propio legislador al momento de crear el derecho positivo; se hace imposible, sin embargo, escudriñar en la intención verdadera o común de los sujetos, en la medida en que será la propia NLTV la que fijará cuál es la divisa aplicable, tal como se desprende del artículo 5.3:

En caso de diferencia de la unidad monetaria, se entenderá que su importe corresponde a la moneda nacional, si uno de sus importes estuviere expresado en dicha moneda. En caso contrario el documento no surtirá efectos cambiarios. Los importes que no consignen la unidad monetaria, se entenderán que corresponden a la moneda nacional. En todos estos casos, el interesado igualmente podrá hacer valer sus mayores derechos frente al obligado, por la vía causal.

14 Emilio Betti, Teoría general del negocio jurídico (Granada: Comares, 2000), 341.

15 Riccardo Guastini, Interpretar y argumentar (Madrid: Centro de Estudios Políticos y Constitucionales, 2014), 25. 


\section{El fraude del acto jurídico y la utilización cartular para tal fin}

El fraude o simulación distingue dos categorías doctrinarias. En primer lugar, el fraude contra la ley correspondiente al derecho internacional privado; es el que utiliza mecanismos que eluden la ley nacional para ampararse en una ley extranjera permisiva; implica una forma de elusión de la ley que encuentra límites en las normas de orden público. Siendo que el presente trabajo no trata sobre el derecho internacional privado, no abordaremos en mayor profundidad el fraude contra la ley.

La segunda categoría es el fraude contra los acreedores, situación que se genera cuando el deudor efectúa actos de disposición o de gravamen con el fin de disminuir su patrimonio o incurrir en insolvencia con la finalidad de sustraerse de sus obligaciones frente a los acreedores. Para lograrlo, se recurre a la enajenación de bienes, el gravamen o la simulación de deudas, o incluso la utilización de testaferros $\mathrm{u}$ «hombres de paja» para mantener los bienes del patrimonio lejos de la propia esfera patrimonial.

El ordenamiento prevé dos mecanismos destinados a dejar sin efecto los actos de disposición o de gravamen fraudulentos. Nos atreveríamos a afirmar que el fraude contra los acreedores encaja en una peculiar forma de simulación, específica, que persigue un objeto concreto: dejar fuera del alcance de los acreedores los bienes que realmente le pertenecen al deudor. Al respecto, el maestro Francisco Ferrara señala:

El fin principal que las partes se proponen al realizar un acto simulado es el de producir una disminución ficticia del patrimonio o aumento aparente del pasivo para, de este modo, frustrar la garantía de los acreedores e impedir su satisfacción ${ }^{16}$.

Los títulos valores han sido utilizados durante mucho tiempo con dicha finalidad; los mecanismos son variados y van desde la utilización de un título de crédito hipotecario, que puede servir para evitar el embargo de bienes inmuebles, hasta el uso de una letra de cambio sin causa aparente en la cual el «aceptante» se obliga frente a un beneficiario — en realidad ficticio — para conseguir una medida fuera del proceso destinada a la anotación de un embargo sobre un bien mueble o inmueble. En otras ocasiones hemos visto la

16 Francisco Ferrara, La simulación de los negocios jurídicos (Madrid: Editorial Revista de Derecho Privado, 1960), 174. 
utilización de cheques de gerencia para evitar poseer en los bancos cuentas susceptibles de eventuales embargos en forma de retención.

También es usual la certificación de cheques para conseguir que la administración tributaria no pueda considerar el activo en un determinado periodo y, de ese modo, pase al periodo siguiente; en este último caso, no se trataría de un fraude propiamente dicho, sino de una dilación producto de una «maña» o «elusión temporal» contable.

Del mismo modo, no es poco usual que el endoso o transmisión de algunos títulos valores a la orden se utilicen para desvincular el título de su causa y lograr, de ese modo, la ansiada autonomía cambiaria que depura el título de las excepciones que el deudor cambiario primigenio pudo haber deducido. Al respecto, el maestro Carlos Gilberto Villegas señala:

El efecto de esta característica de los valores es que al poseedor de buena fe no le pueden ser opuestas excepciones personales, fundadas en relaciones con anteriores tenedores. Señalemos desde ahora que la adquisición de mala fe del valor por parte del tenedor, excluye el principio de autonomía y hace comunicables las excepciones personales exceptio doli $i^{17}$.

El artículo 195 del Código Civil describe la acción pauliana o acción de ineficacia, debiéndose diferenciar esta de la ineficacia de un título valor que corresponde a un concepto distinto. La acción pauliana busca dejar sin efecto los actos fraudulentos realizados por el deudor, sean estos actos onerosos o gratuitos, reservando dos vías procesales: la del proceso de conocimiento para los primeros y la del proceso sumarísimo para los segundos. Es ahí donde se presenta una interesante problemática que vincula al acto jurídico con el derecho cartular.

El derecho cambiario se rige por principios que le son propios, tales como la abstracción y la autonomía cambiaria. En tanto que, si un sujeto legitimado con una eventual acción pauliana pretendiese dejar sin efectos actos de disposición o gravamen contenidos en un instrumento cartular, se podría hallar frente a la eventual transmisión simulada del título mediante un endoso; y siendo que, conforme al principio de buena fe, esta se presume y la mala fe debe ser probada, nos hallamos frente a un problema probatorio muchas veces infranqueable, al ser el endoso de un título valor no solo un acto unilateral

17 Carlos Gilberto Villegas, Títulos valores y valores negociables (Buenos Aires: La Ley, 2004), 55. 
y no recepticio, sino también abstracto; no expresa causa, salvo algunas excepciones como el endoso en fideicomiso.

Los títulos valores también son utilizados para enmascarar la ilicitud mediante la simulación de créditos concedidos dentro de los márgenes legales, vale decir, sin superar la tasa máxima de intereses que fija el BCRP. La emisión de un pagaré puede señalar la entrega o conformidad de una suma mayor a la realmente recibida, evitando, de esa manera, la nulidad del título valor por intereses ilegales, en estricta aplicación del artículo 21 de la NLTV.

Artículo 21.- Nulidad del título valor por intereses ilegales.

21.1 Podrá deducirse la nulidad del título valor obtenido por el tenedor en representación o en pago de préstamos con intereses usurarios o prohibidos por la ley, sin perjuicio de la responsabilidad penal a la que hubiera lugar, según la ley de la materia.

21.2 En caso de que el título valor que contenga tales intereses hubiera sido transferido, la nulidad señalada que no surja de su texto, no podrá invocarse contra el tenedor de buena fe que lo haya adquirido observando las normas que rigen su circulación.

Queda claro, entonces, que la naturaleza peculiar del derecho cambiario, regido por principios jurídicos que le son propios, generan una dicotomía respecto de los referidos a la teoría negocial, sin ingresar a la diferenciación de acto jurídico con negocio jurídico, por no corresponder a la finalidad del presente análisis. Los diversos supuestos de fraude, simulación y fin ilícito, mediante la utilización de instrumentos cambiarios, son amplios; las limitaciones de orden probatorio resultan evidentes.

Ambas ramas pertenecientes al derecho privado, concretamente al derecho civil y al derecho mercantil, han evolucionado desde teorías propias, habiéndose generado un tratamiento independiente derivado de los principios que le son aplicables. El presente artículo ha buscado efectuar una primera aproximación y comparación entre ambos campos del saber jurídico. 


\section{Referencias}

Albaladejo, Manuel. El negocio jurídico. Barcelona: Bosh, 1993.

Basadre Ayulo, Jorge. Historia del derecho. Lima: Editorial San Marcos, 1997.

Betti, Emilio. Teoría general del negocio jurídico. Granada: Comares, 2000.

Broseta Pont, Manuel. Manual de derecho mercantil. Madrid: Tecnos, 1994.

Espinoza Espinoza, Juan. Acto jurídico negocial: análisis doctrinario, legislativo y jurisprudencial. Lima: Gaceta Jurídica, 2008.

Ferrara, Francisco. La simulación de los negocios jurídicos. Madrid: Editorial Revista de Derecho Privado, 1960.

García-Pita y Lastres, José Luis. Introducción al derecho de los títulos valores y de las obligaciones mercantiles. Santiago de Compostela: Tórtulo, 2002.

Guastini, Riccardo. Interpretar y argumentar. Madrid: Centro de Estudios Políticos y Constitucionales, 2014.

León Hilario, Leysser Luggi (coord.). Derecho de las relaciones obligatorias. Perú: Jurista Editores, 2007.

León Hurtado, Avelino. La voluntad y la capacidad en los actos jurídicos. Santiago de Chile: Editorial Jurídica de Chile, 2000.

Mans Puigarnau, Jaime. Los principios generales del derecho: repertorio de reglas, máximas y aforismos jurídicos con la jurisprudencia del Tribunal Supremo de Justicia. Barcelona: Bosch, 1978.

Peña Nossa, Lisandro. Curso de títulos-valores. Bogotá: Themis, 1992.

Pietrobon, Vittorino. El error en la doctrina del negocio jurídico. Madrid: Editorial Revista de Derecho Privado, 1971.

Vial del Río, Víctor. Teoría general del acto jurídico. Santiago de Chile: Editorial Jurídica de Chile, 2003.

Villegas, Carlos Gilberto. Títulos valores y valores negociables. Buenos Aires: La Ley, 2004. 
Piero Da Giau Roose

\section{Leyes, sentencias y otros documentos legales}

CAS 2928-00 Lima, El Peruano, 2 de febrero de 2001.

Ley de Títulos Valores (16587), 1967.

\section{Sobre el autor}

Magíster en Derecho Civil y Comercial y abogado por la Universidad de San Martín de Porres. Egresado del Programa de Estudios Avanzados en Derechos Humanos de la American University Washington College of Law (Estados Unidos). Docente de diversas instituciones de educación superior: Universidad ESAN, Universidad, Femenina del Sagrado Corazón (Unifé), Escuela Militar de Chorrillos Francisco Bolognesi, Academia de la Magistratura, Escuela Nacional de Control de la CGR, y de posgrado de la Universidad Nacional José Faustino Sánchez Carrión. 